\title{
Research on the Application Mode of Computer SimulationTechnology in the Study of Economic Law
}

\author{
Hui Wang \\ Ningxia Justice Police Vocational College, Yinchuan, China
}

Keywords: economic law learning; computer simulation technology; advantage analysis; model building

\begin{abstract}
Economic law is an important course of economic management related professions. With the increasing development of economy, the occupation level of this industry has a more and more stringent requirements. How to quickly and effectively learn the economic law is an issue of concern. This paper mainly studies the introduction of computer simulation technology into the study of economic law. Firstly, it introduces the meaning of computer simulation technology. Based on that, it has analyzed the advantages of application of computer simulation technology in the study of economic law, has constructed the learning model of economic law based on computer simulation technology. Through the research analysis, it has obtained the conclusion that the introduction of computer simulation technology in the study of economic law can stimulate interests, and effectively improve the learning efficiency.
\end{abstract}

\section{Introduction}

With the increasing development of economic social, economic law plays a more and more important role in the national life. How to quickly learn the content of economic law, to master the application skills is an issue to be solved for the industry practitioners. The development of the computer simulation technology is an opportunity to solve the problem [1,2]. Computer simulation technology mainly refers that the computer system builds the three-dimensional space model of satisfying used objective according to the related data information. Through simulation of human visual, auditory and other sensory perceptions, it formed virtual human-computer interactive learning space to enable the learners to feel kind of immersive; on the other hand, it broke the hardware facilities' shackles of traditional way of learning, and improved the learner's cognitive ability and ability to accept [3]. The computer simulation technology synchronously fuses the image with sound to make the virtual learning space abnormally "real", so that learners can be personally on the scene to learn, increase the learning interest, also deepen the impression of learning the knowledge to make the learners flexibly master and apply [4]. At present, our country has a lot of researches in the field of computer simulation technology. For example, Fu Ailing, Li Xiaorong, Tian Jinhong have studied and analyzed teaching mode of microbial pharmaceutics curriculum by introducing the computer simulation technology in the course of Microbial Pharmaceutics. By building a model to evaluate the effect of teaching mode, it obtained the conclusion that computer simulation teaching could improve students' interest in learning, and was very helpful to teaching. Wang Haohua, Dan Ye have put forward applying computer simulation technology into the teaching of higher mathematics in the paper of realization and application of computer simulation technology in the higher mathematics teaching. Through the use of MT software to make teaching positive analysis, they obtained the conclusion that the use of computer simulation technology could significantly improve the learning ability of students.

\section{The connotation of the computer simulation technology}

Computer simulation technology mainly uses computer systems to simulate the human visual, auditory and other sensory perceptions to form a multidimensional virtual space of sense, so that participants have a feeling of being personally on the scene [5]. The process is as shown in Figure 1. 
As shown in Figure 1, usually, a computer simulation system is mainly composed of multimedia computer system, video display system, sound system, human sensory feedback system, human body tracking and positioning system.

The realization of computer simulation technology emphasizes the main effect of the person. It uses the space environment dreamed up by computer simulation technology to fuse with the objective things and people. In this environment, participants can obtain intuitive understanding and perception of the objective things, to enhance the impression of objective things in the minds of the participants [6,7]. Effect of this technique in the learning of theory of knowledge is more obvious. The process is shown in Figure 2.

Realization of computer simulation technology are supported by several techniques [8]: (1) the construction technology of objective environment model builds virtual space model according to the use requirement and purpose; (2) the image video generation technology simulates the real environment or data operation process; (3) human machine interaction technology uses the tracking positioning system to record and transmit various actions of body into the computer center system to make the data processing and the expected results.

Computer simulation technology mainly has the following characteristics [9,10]: (1) multidimensional sensory. Computer simulation technology through simulating virtual reality environment, not only has the vision also has the auditory, olfactory and other sensory properties, which can achieve a variety of human sense organs; (2) Fusion sense. With the development of computer simulation technology, the real degree of virtual environment is more and more high, and the feeling of user being personally on the scene is more and more real. Making it fuse into the virtual environment can enhance the user's impression; (3) Interaction. Virtual environment simulated by computer not only can feedback the information of objective things, can also reflect appropriate role information of users in the process of users' participation, which is a process of interaction.

\section{Advantage analysis of application of computer simulation technology in the study of economic law}

Study of traditional economic law mainly relied on teachers or independent reading related books. Whether it was the kind of learning approach, it was too monotonous, stiff, so that learners' schoolweariness easily produced in the learning process, and learning initiative was not high [11]. The application of computer simulation technology provides new ways for economic law study. Through building virtual learning environment makes learners be involved which has broke the fixed pattern of traditional learning, and improved the learning interests.

This paper compared the achievements of the two methods of learning, and then analyzed the advantages of application of computer simulation technology into the study of economic law. First of all, it assesses the learning method of traditional pattern. Assume that the achievements of evaluation results are $I=\int_{D} f(p) d_{p}$. D represents the statistical results of achievements performance, and achievements probability reaching excellent standard in D is expressed by $\rho(p)$. Assuming that $F(p)=\left\{\begin{array}{c}f(p) / \rho(p), \rho(p) \neq 0 \\ 0, \rho(p)=0\end{array}, p_{1}, p_{2}, \cdots, p_{n}\right.$ is the selected achievements result in $\mathrm{D}$. it can assume that $I=\int_{D} f(p) d_{p}=E[F(p)]<+\infty$, then $I=\hat{F}_{n}=\frac{1}{n} \sum_{i=1}^{n} F\left(p_{i}\right)$. Usually, the achievements result D obtained by statistic has two-dimensional. So it can obtain the achievement probability of excellent standards which can breached is $\rho(p)=\left\{\begin{array}{l}0 \\ \frac{1}{v_{0}}, p \in D \text {, so } F(p)=V_{D} \cdot f(p) \text {, namely }\end{array}\right.$ 


$$
I=\hat{F}_{n}=\frac{1}{n} \sum_{i=1}^{n} F\left(p_{i}\right)=\frac{V_{D}}{n} \sum_{i=1}^{n} f\left(p_{i}\right)=V_{D} \cdot f \hat{(p)}
$$

Assuming that the probability distribution of $X$ is $\rho(x), a \leq x \leq b$, then $E(f(X))=\int_{a}^{b} f(x) \rho(x) d x$. When it calculates the results of evaluation achievements in the interval (a, b), it can firstly transform the $\mathrm{x}=\mathrm{a}+\quad(\mathrm{b}-\mathrm{a}) \mathrm{u}$, then the calculation is as follows $\int_{0}^{1} f(x) d x=(b-a) \int_{0}^{1} f(a+(b-a) u) d u \approx \frac{b-a}{n} \sum_{i=1}^{n} f\left(a+(b-a) u_{k}\right)$. The results obtained by statistic are put into the formulation; it can get desired achievements evaluation results of learning methods of traditional economic law.

The above is the process of achievements evaluation on learning model of the economic law. The following evaluates learning achievements of economic law in the new mode based on the MATLAB algorithm of computer simulation technology.

Setting $\mathrm{k}=\mathrm{k}+1$, in the range of $\left[X_{d}, X_{m}\right]$, the reaching of excellent standards' achievements probability has $\mathrm{n}$, it is regarded as $f\left(x_{n k}\right)>\min _{1 \leq i \leq n}\left\{f\left(x_{i}\right)\right\}$, so $F_{0}(k)=\min \left\{F_{0}(k-1), f\left(X_{n k}\right)\right\}$. When $F_{0}(k)<\xi$, it can get $f_{x}=x_{n k}$ is the achievements evaluation result of study of economic law under the new mode. When $F_{0}(k)>\zeta$ is established and $F_{0}(k)=F_{0}(k-1)$, it can use $F_{0}(k)=\min \left\{F_{0}\left(k-1, f\left(x_{n k}\right)\right)\right\}$ to calculate to get the achievements evaluation result of study of economic law under the new mode. When it is uncertainty of achievements probability reaching excellent standard of economic law learning under the new mode, it can be calculated by using the Matlab algorithm. It is as shown below.

$\mathrm{n}=10000 ; \mathrm{xu}=\mathrm{pi} / 2 ; \mathrm{xd}=0 ; \mathrm{k}=1 ; \mathrm{fx}(1)=1000 ; \mathrm{d} 0=1 \mathrm{e}-4$;

While(fx(k)>1e-5)

$\mathrm{k}=\mathrm{k}+1 ; \quad \mathrm{x}=$ unifrnd(xd,xu,n,1); $\quad \mathrm{y}=\exp (-\mathrm{x} .3)-\tan (\mathrm{x})+800 ; \quad \mathrm{fx}(\mathrm{k})=\mathrm{fx}(\mathrm{k}-1) ; \quad$ for $\quad \mathrm{i}=1$ :n $\quad$ if $\operatorname{abs}(y(i)<=f x(k)) ; f x(k)=a b s y((i x))=f x(k)$; end end $f r=x ; d=d 0 / k ; x u=f r+d ; x d=f r-d ;$ end

TABLE I. THE MATLAB CALCULATION RESUlTS

\begin{tabular}{|c|c|c|c|c|}
\hline $\mathbf{k}$ & $\mathbf{1}$ & $\mathbf{2}$ & $\mathbf{3}$ & $\mathbf{4}$ \\
\hline$f_{x}(k)$ & 1000 & 41.95 & 12.2 & 0.0043 \\
\hline $\mathbf{k}$ & $\mathbf{5}$ & $\mathbf{6}$ & $\mathbf{7}$ & $f_{r}$ \\
\hline$f_{x}(k)$ & $5.74 \mathrm{e}-5$ & $1.27 \mathrm{e}-5$ & $2.69 \mathrm{e}-5$ & 1.5685 \\
\hline
\end{tabular}

It can be seen from table 1 , function $f_{x}(k)$ is monotone decreasing in the interval of $\left[X_{d}, X_{m}\right]$, so the evaluation result $f_{r}(k)=1.5685$ is the achievements evaluation result based on the study of economic law of computer simulation technology, which takes the far advantages over the above calculated achievements results of traditional economic law learning methods. We can see that the computer simulation technology applied to the study of economic law can effectively mobilize the interest of learners, and obviously improve the learning performance achievements.

\section{Construction of learning model of economic law based on computer simulation technology}

Construction of learning model of economic law based on computer simulation technology mainly uses the computer system to build remote virtual terminal, so that learners can at any time, any place go into the simulation of spatial learning, break the restriction of objective conditions in the traditional learning methods. The virtual model is shown in Figure 3. 


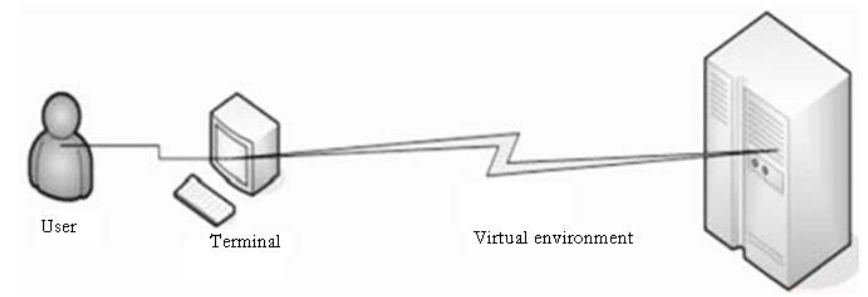

Figure 3. Schematic diagram of remote virtual model

It can be seen from figure 3, based on the computer simulation technology, the virtual model of remote economic law learning is mainly composed by the user, the computer terminal, remote virtual environment the three part. Systems of computer terminal mainly applied are the VRP editor, Sketchup, 3DMAX and so on. The economic law learning patterns based on computer simulation technology can use Sketchup and 3DMAX software to build different virtual learning environment according to the needs of the user. It is shown in Figure 4.

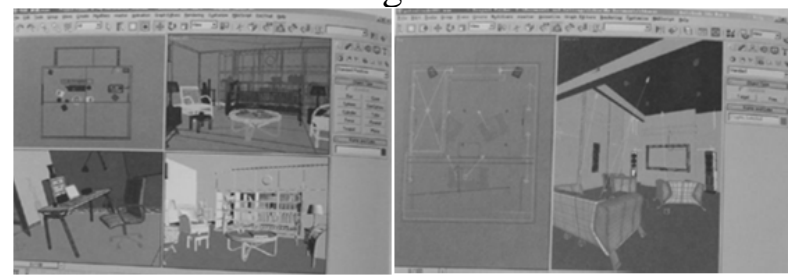

(a)

(b)

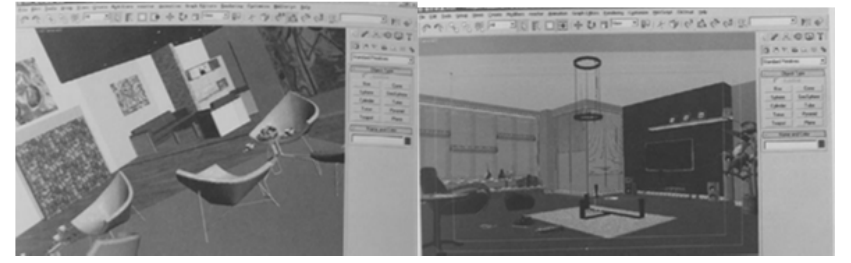

(c)

(d)

Figure 4. Schematic diagram of different virtual learning environment

As shown in Figure 4, Sketchup, 3DMAX software have provided a option of virtual learning environment for the user. The user can build a suitable learning environment according to their preferences and needs, which can maximize the enthusiasm for learning, improve their learning initiative.

It is the process of human-computer interaction after virtual learning environment is successfully constructed. This process is to be realized by the VRP editor. The VRP editor is simple to operate. The user with preliminary basic computer can quickly use. In addition, the most prominent feature of VRP editor is the strong human-computer interaction. The user can operate all kinds of virtual environment according to their own needs. It is convenient to make dialogue and exchanges with the virtual environment.

By means of basic software, economic law learners can according to their own situation to construct needed learning model, so that they can "hands-on" experience all kinds of learning environment. It increases the learning interest through human-computer interaction, which greatly improves the efficiency of economic law study.

\section{Conclusion}

Improving the efficiency of learning was the first considered question of any learning models. The way of traditional economic law learning was monotone and rigid, so as to the majority of learners spent a lot of time but efficiency was not high in the learning process. The introduction of computer simulation technology had broken the inherent mode of traditional learning. Through the construction of the virtual learning environment, it enabled the learners to have the kind of being personally on the scene, and increased the learning interests. By "hands-on", it deepened the learner's impression, which greatly improved the efficiency of learning. In today's society of the everaccelerating pace of life, this learning mode could save valuable time, which was worthy to be popularized in the national scope. 


\section{References}

[1] Ailing Fu, Xiaorong Li, Jinhong Tian. The application of computer simulation technology in the course of microbial pharmaceutics [J]. Journal of Southwestern Normal University, 2012 (1): 56-57.

[2] Haohua Wang, Ye. The realization and application of computer simulation technology in the teaching of higher mathematics [J]. Journal of Hainan University Natural Science Edition, 2012 (6): 31-32.

[3] Bei Ma, Jinhui Xia. The application of computer simulation and simulation technology in medical education [J]. Chinese higher medical education, 2011 (1): 45-47.

[4] Xiaofang $\mathrm{Xu}$, Xiaohua Wu. Analysis on the application of case teaching in the teaching of economic law [J]. Education and occupation, 2010 (30): 121-123.

[5] Xiaoming Chen, Zuying Gao, Zhiwei Zhou etc. The human-machine interface evaluation system based on computer simulation technology [J]. Atomic energy science and technology, 2011(1): 89-93.

[6] Wei Shen, Liwen Xia. Virtual reality technology [M]. Beijing: Hope Electronic Press, 2010:1825.

[7] Youshuang Wei, Xianglong Yang, Fei Wang. Virtual reality and system simulation [M]. Beijing: National Defense Industry Press, 2010: 120-137.

[8] Jianmei Wang, Xu Zhang, Yong Wang, etc. Development status, policy of virtual reality technology in the United States and its enlightenment to China [J]. Science and technology management research, 2010(14): 37-40.

[9] Grigore C.Burdea, Phili ppe Coiffet. Virtual Reality Techonlogy [M]. Wiley-IEEE Press, 2010: 304-310.

[10] TOFIL N M, BENNER KW, WORTHINGTON M A, et a1. Use of Simulation to Enhance Learning in a Pediatric Elec-tire [J]. Am J Pharm Educ, 2010,74(2): 670-675.

[11] BERGSTR()M R. The Role of the Pharmaceutical Industry in Meeting the Public Health Threat of Antibacterial Resist-ance [J]. Drug Resist Updat, 2011,14(2): 1101-1106.

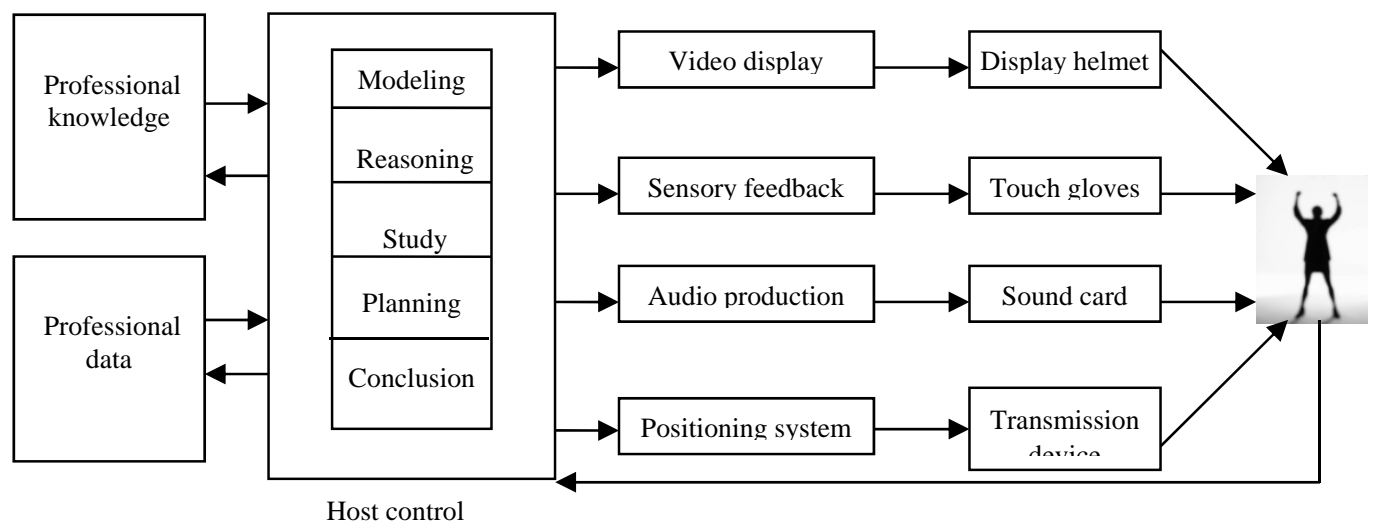

Figure 1. Schematic diagram of process of computer simulation technology 


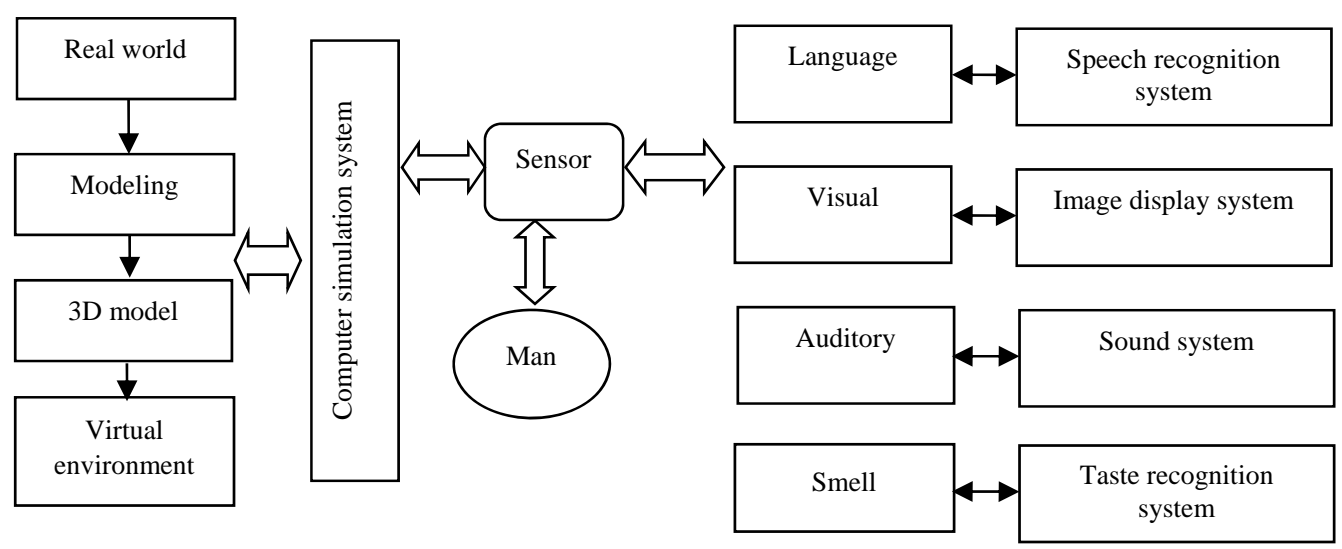

Figure 2. Flow chart of study of computer simulation system 